\title{
Optimization of sustainable buildings envelopes for extensive sheep farming through the use of dynamic energy simulation
}

\author{
Maria Elena Menconi, David Grohmann \\ Department Uomo e Territorio, University of Perugia, Italy
}

\begin{abstract}
Extensive sheep farming can be seen as a marginal market, compared to other livestock and agricultural activities, taking into account only the economic absolute values. But for many rural marginal areas within the European Community member states, in particular for those located in the Mediterranean area on hills or mountains with high landscape value, extensive sheep farming is not only the longest practiced animal farming activity, but also the most interesting considering its adaptability to the territorial morphology and the restrictions that have been established over the years in terms of sustainable rural development practices.

At the moment, most of the structures used in this type of farming are built using low cost and sometimes recycled, but often unsuitable, materials. Few specific studies have been carried out on this particular issue assuming, presumably, that the very low profit margins of these activities made impossible any restructuring.

Taken this into account, the new Rural Development Plans that will be issued in 2014 will surely contain some measure dedicated to innovations in farming structures and technology towards facilitating the application of the principles of energy optimization. This is the framework in which the present research has developed.

The software that has been applied to perform the energy optimization analysis is the dynamic energy simulation engine Energy Plus.

A case study farm has been identified in the small village of Ceseggi (PG), situated in Central Italy. For the case study optimum thermo hygrometric conditions have been identified to ensure the welfare of animals and operators and it has been hypothesized the insertion of an ideal HVAC system to achieve them. Afterwards were evaluated the different energy requirements of the building while varying the insulation material used on the vertical surfaces. The greater goal is to verify
\end{abstract}

Correspondence: Maria Elena Menconi, Department Uomo e Territorio, University of Perugia, Italy

Key words: Dynamic energy simulation, sustainable building envelopes, vertical surface insulation, extensive sheep farming.

CCopyright M.E. Menconi and D. Grohmann, 2013

Licensee PAGEPress, Italy

Journal of Agricultural Engineering 2013; XLIV(s2):e42

doi:10.4081/jae.2013.s2.e42

This article is distributed under the terms of the Creative Commons Attribution Noncommercial License (by-nc 3.0) which permits any noncommercial use, distribution, and reproduction in any medium, provided the original author(s) and source are credited. which could be the best insulation material for vertical surfaces from energy requirement, primary energy and cost points of view and to verify as well if it would be possible to achieve optimum environmental conditions by using only passive solutions.

\section{Introduction}

As a result of sensitization to the issues of energy saving, efficient use of resources and fight against pollution, the trend in European Union regulation is to place more stringent requirements on the energy performance of buildings, (2002/91/EC, 2012/27/EC) acknowledged by the Italian National Energy Strategy (D.lgs 192/2005, D.M. 8/03/ 2013). Numerous studies have amply demonstrated that the best solutions related to energy conservation should be strongly anchored to the geographical context of reference (Znouda E. et al., 2007; Ihm P. and Krarti M., 2012) and then consider all aspects as the enclosure, the orientation, the shape (Wang K.S.Y. and Yik F.H.W., 2004), the distribution of the functional areas, the materials, the openings, the loads, the energy sources (http//www.activehouse.info/). There are many tools for the verification of the energy performance of buildings that differ in the level of detail required in the input data and then in the ease of obtaining the results and their reliability.

The main distinction is between stationary and dynamics simulations. Stationary simulations use as input data average monthly temperature and radiation, instead simulations carried out under dynamic conditions use as input a weather file that has a hourly scan of the main meteorological variables, allowing much more realistic and complete surveys. Energy Plus is one of the most well-known free software dedicated to the simulation of building energy working under dynamic conditions. This software was elaborated to primarily assess the performance of residential buildings. There are also publications of the same kind for livestock infrastructures, but are mostly dedicated to cattle and swine intensive farming (Jäkel K., 2003; Kraatz S. and Berg W., 2007; Fabrizio E. and Airoldi G., 2012).

Extensive farming, due to its generally lower management costs in comparison with intensive practices, and especially dairy sheep farming, until now has received little attention.

In this paper is used Energy Plus applying it to a dairy sheep farming. Sheep farming can be considered a niche market within the vast framework of agriculture activities, representing just 7\% of the European livestock market (European Commission, 2012).

Especially in the last decade, the entire national agriculture production has identified, in quality products, strongly connected with the territorial context in which are produced, their most important resource (ARSIA, 2006). Olive oil and wine have been trailblazer products in this regard and sheep's products (milk, meat and wool) could represent equally important resources for those areas in which they are produced. Extensive sheep farming plays other pivotal roles; one of this 
is the territorial protection in marginal rural territories, with a low level governance, otherwise destined to depopulation and abandonment; moreover can be considered one of the livestock activities more sustainable from an environmental point of view (Thompson R., 2009).

The buildings in service of extensive sheep farming are quite heterogeneous in terms of material and geometries (Chiappini U. et al., 1994), having been realized in a rather extended period, but it can still be clearly identified a trend toward low cost materials and structures greatly simplified from the design point of view (U.N.A.P.O.C., 1992).

This generally translates into greater difficulties in the control of environmental conditions within the structures and the lack of dedicated HVAC systems also contributes to worsen the problem (Capronese M., 2008).

Most of the contact with the external environment of a building occurs through opaque surfaces such as walls, roof and floor. It is evident the role played by these elements in maintaining comfort in indoor environments. In this regard, for the design of a building so that it can be affected as little as possible by the external conditions and temperature changes or when operating on an existing building, the first option is to intervene on the thermal inertia of the opaque surfaces. The thermal inertia can be increased by using high-density materials, increasing the capacity of accumulation of the heat. It is also possible to intervene with cavities or with insulating coatings, which have a further damping effect of the oscillations of internal temperature. The outer envelope becomes the first element on which is possible to work for improving the energy efficiency of a building.

This paper is focused on existing buildings, exploring the possibilities offered by vertical surfaces in order to identify the best solutions in terms of overall energy savings (reducing building energy consumption and primary energy embodied in the selected materials) and reduction intervention costs.

\section{Material and methods}

The developed methodology includes the following steps (Figure 1): 1 Construction of the 3D model of the building. For this purpose is possible to use the free software SketchUp (http://www.sketchup. com/int//en/download/index.html) that allows you also to define the building orientation with respect to the wind rose.

2 Definition of the thermal zones. Thanks to an interesting plug-in called Open Studio (http://apps1.eere.energy.gov/buildings/energyplus/energyplus/openstudio.cfm) is possible to draw in SketchUp the building directly divided into thermal zones, which are not determined by the internal subdivisions of the building, but by the volumes with constant air temperature (for example, two contiguous rooms maintained at the same temperature are part of the same thermal zone).

3 At this point is possible to import the file into Energy Plus (http://apps1.eere.energy.gov/buildings/energyplus/energyplus_dow nload.cfm), in IDF format, and to characterize the properties of building components (n. layers, materials, layout) 4 - Within the component of Energy Plus called IDF Editor is also possible to define the characteristics of the used materials (thickness, conductivity, specific heat, density).

5 Then internal gain space data must be compiled for every thermal zone (for example for animals housed the internal gain tool requires to divide them into sheep and lambs and to define their level of activity and the timetable of their presence in the stable; similarly for operators; for lighting requires lighting level (W) and switching times; for electric equipment design level and switching timetable; for zone infiltration requires value and method of design of the flow rate)

6 Configuration of an ideal HVAC system that will be used to estimate the margin of improvement of the energy performance of the building. Is important to emphasize that the choice of an ideal system has been made because in real situations, in the sheepfold buildings is not present an HVAC system. The objective is to have a reference value with which to compare the various proposed solutions, with a more ambitious overall goal of verifying the possibility to ensure the optimum environmental conditions (Chiumenti R., 1987) for animals and operators exclusively through design solutions and insulation, without the introduction of an actual HVAC system; The considered optimal and critical temperature ranges are the following:

Sheep optimal T range $10-17^{\circ} \mathrm{C}$; critical T range $6-25^{\circ} \mathrm{C}$ Lamb 0 -2 weeks optimal T range $20-22{ }^{\circ} \mathrm{C}$; critical T range $17-25^{\circ} \mathrm{C}$ Lamb 3-4 weeks optimal T range $15-18{ }^{\circ} \mathrm{C}$; critical T range $13-25^{\circ} \mathrm{C}$

7 Acquisition of a weather file for the selected location. The weather data file contains hourly data (8760 data per year) for 27 climate parameters, Numerous weather files are available on the U.S. Department of Energy website (http://apps1.eere.energy.gov/buildings/energyplus/weatherdata_about.cfm?CFID $=775268 \&$ CFT0$\mathrm{K} \mathrm{E} \mathrm{N}=44 \mathrm{~d} \mathrm{f} \mathrm{f} \mathrm{c} \mathrm{e} \mathrm{d} 5$ c 01 a 022 - A 76 E 7 B E 2 - E 559 - 85 A F AD92C8E8EDC0CCBB), once the location is identified (name, latitude, longitude, time zone, elevation) the closest available weather file is selected. The Weather File and the IDF are the two input file of the Energy Plus component EP-launch, this tool allows to run the simulation of the building energy performance for a user-defined period (in this work is one year). Therefore, at this point, it is possible to make a first evaluation of the energy that is required by the building in the current state (defined reference) to achieve and maintain during the year the optimum conditions for animals and operators.

8 Construction of alternative IDF models, varying the caulking materials used to insulate the vertical walls, using natural and synthetic materials;

9 Comparison of the various results, in term of total site energy, primary energy and cost, using the Simple Additive Weighting (SAW) multi criteria analysis;

10Evaluation of the best solutions concerning insulation's options.

\section{Results}

\section{Case study}

The developed methodology was applied in a dairy sheep livestock farm building. The case study sheepfold is located in Ceseggi, part of the municipality of Sellano (Umbria region- Central Italy) and about 1 $\mathrm{km}$ away from the border with the Marche region. The building is situated at south-east of Sellano city and its elevation is $974 \mathrm{~m}$ a.s.l..(Figure 2)

The building is organized in three structures: the stable, the milking parlor and the warehouse and occupies a total area of $766 \mathrm{~m}^{2}$ and a volume of $3648,31 \mathrm{~m}^{3}$ (Figure 3). The building is exposed to the NorthEast along the longitudinal axis of the fold, the openings are represented by aluminum doors and by single glass aluminum frame windows. The gross wall area is 732,87 square meters and the windows opening area is 35,84 square meters, with a window-wall ratio of $4,89 \%$. The $3 \mathrm{D}$ model of the building is represented in Figure 4.

Construction materials consist of steel for structures such as pillars and trusses, concrete blocks for the infill and concrete slabs for cover. 
The sheepfold, at full capacity, can accommodate about 200 sheep. The births take place twice a year, in winter from January to March and during the summer from June to August.

For each of these periods there are approximately 80 births. The sheep are housed the whole day in the stable only in winter; in summer only those with lamb. For the rest of the year all the animals are located in the barn only at night. For the periods from April to June and from September to December, the animals are milked twice a day. For these periods, in the simulations, values of activity level are associated to sheep, lambs and operators (Table 1), in order to identify the internal gain values.

The electric equipment is represented by a pump and a compressor serving the milking parlor and a mill and hay cutting machine in the warehouse.

The selected weather file is the Perugia one.

The choice of the weather file of Perugia represents an approximation and to get more accurate results would be necessary to have a more specific weather file. This choice has been made as, form the

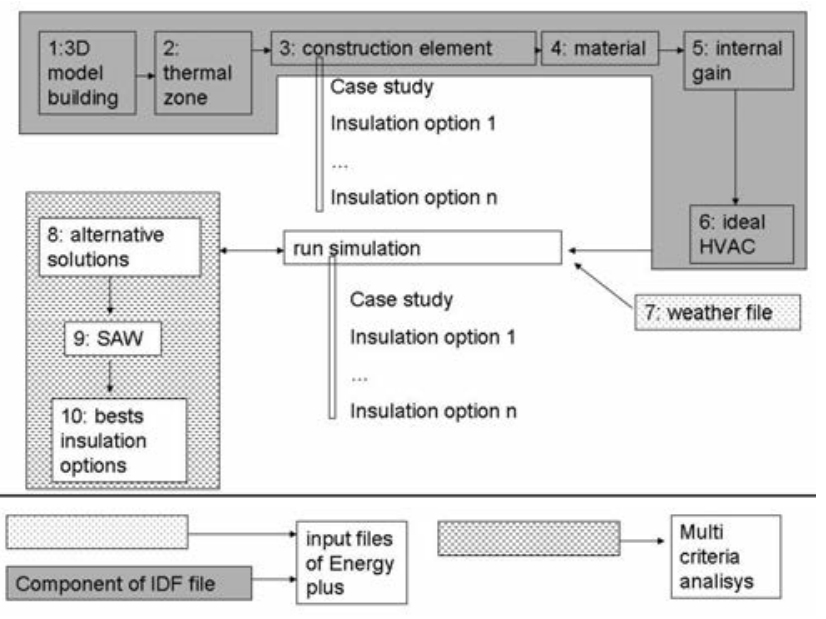

Figure 1. Methodology flowchart.

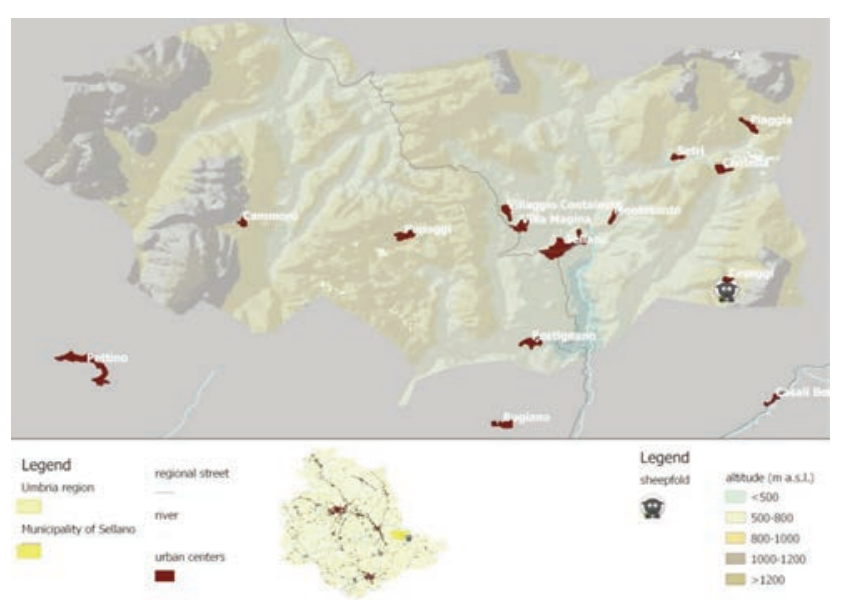

Figure 2. Location of the study case sheepfold. available dataset from the U.S. Department of Energy, this Perugia dataset is the best fitting one (http://apps1.eere.energy.gov/buildings/ energyplus/cfm/weather_data3.cfm/region=6_europe_wmo_region_6/ country=ITA/cname $=$ Italy).

The present work provides the simulation, via Energy Plus, of the thermal behavior of the case study building adding to the vertical opaque surfaces an outer $1 \mathrm{~cm}$ layer of plaster and an inner layer of 5 $\mathrm{cm}$ of insulation.

The insulating materials to be used as design options have been selected from the Umbria Regional pricing 2012 (http://www.operepubbliche.regione.umbria.it/Mediacenter/FE/CategoriaMedia.aspx?idc $=32$ $3 \&$ explicit=SI) choosing only simple insulating panels for vertical surfaces, which are the most economical solutions available.

The characteristics of the various materials were taken, when pres-

Table 1. Activity levels

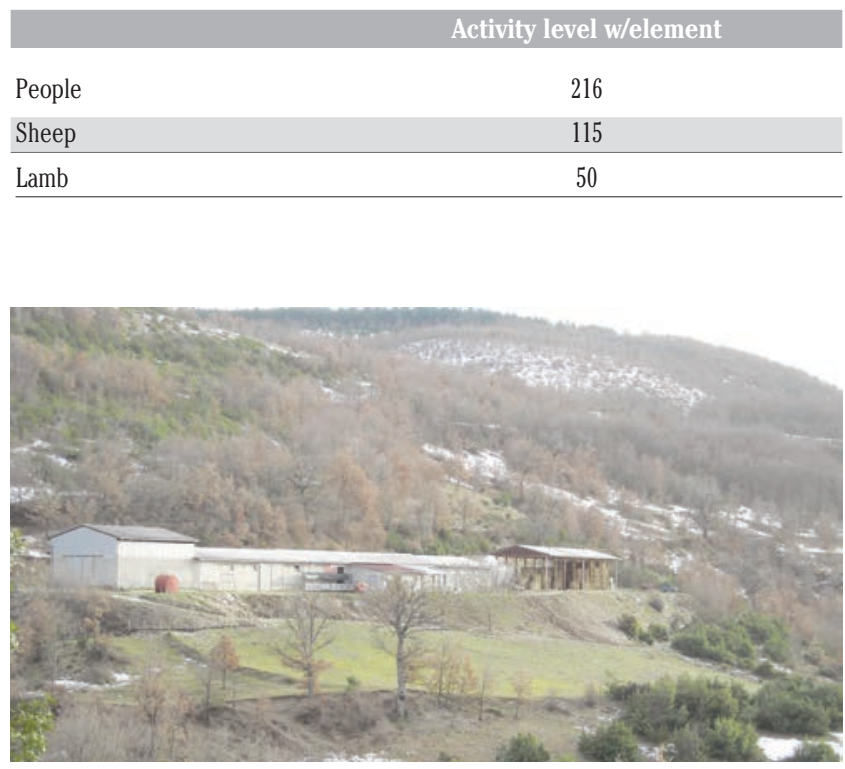

Figure 3. Case study sheepfold.

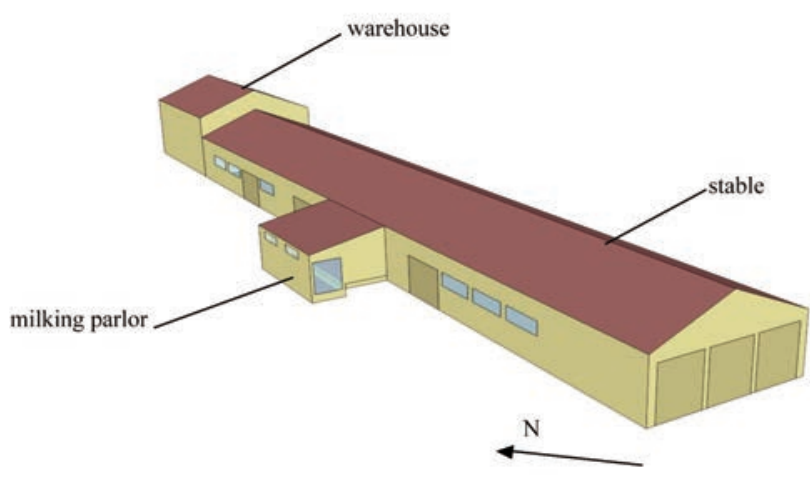

Figure 4. Case study sheepfold 3D model. 
ent, always in the same Umbria Regional price list and supplemented by findings from other sources (Rossi M., 2007; Emilia Romagna Regional price list, Chamber of Commerce of Verona price list)

Nine internal insulation materials were evaluated: 5 of natural origin, and 4 of synthetic origin (Table 2).

\section{Discussion of results}

The results of the simulation (Figure 5 and 6) show that introducing an insulating layer a substantial energy saving it's achievable, between $10-12 \%$, in term of Site Energy (GJ/year), where Site Energy indicates the amount of heat and electricity consumed by the building .

Both synthetic and natural materials, as was to be expected, can achieve excellent results in term of thermal inertia.

Another parameter that should be taken into account is the Primary Energy Input (PEI) of the various materials, in order to embody in the comparison the sustainability aspects, as well.

PEI is a measure of the non renewable resources consumed for the production of a certain good.

Comparing the Site Energy and the PEI for natural and synthetic materials (fig. 7) it is evident that natural materials have a significant lower embodied energy, which would lead the choice of the most suitable material in their direction. On the other hand, under such difficult economic conditions, every costs and supplementary outlay must be carefully considered to avoid overloading the enterprises financial balances. This leads to the difficult task of singling out a price for every material used in the simulations.

The price of construction materials depends by regional price lists that are, generally, updated yearly. In this work the Umbria Regional pricing 2012 is used to define different prices, because the case study building is located in Umbria. One of the simplest multicriteria analysis techniques, the Simple Additive Weighting (Alireza A. et al., 2010), can help us identifying the best insulation solution on the basis of these 3 parameters (Site Energy, PEI, cost; Table 3). Its formula is as follows:

$$
S_{i}=\frac{\sum_{j=1}^{n} w_{j} x i_{j}}{\sum_{j=1}^{n} w_{j}}
$$

where the counter $i$ is related to the alternatives (the alternative 0 relative to the non-intervention and the other relative to the various insulation materials for the vertical wall) and ranges from 1 to 9 , the counter $j$ is related to the considered parameters and varies from 1 to $3, w$ is the weight assigned to each parameter and $x$ is the value that each alternative $i$ assumes with respect to each parameter $j$, appropriately normalized. We have chosen to assign to all the parameters the same weight $w_{j}=1, j: 1-3$, normalizing their values with the minimum and maximum value criterion (equ.2). This linear normalization allows having values evenly distributed inside a closed variation interval [0$1]$.

$$
S_{i}=\frac{\sum_{j=1}^{n} w_{j} x i_{j}}{\sum_{j=1}^{n} w_{j}}
$$

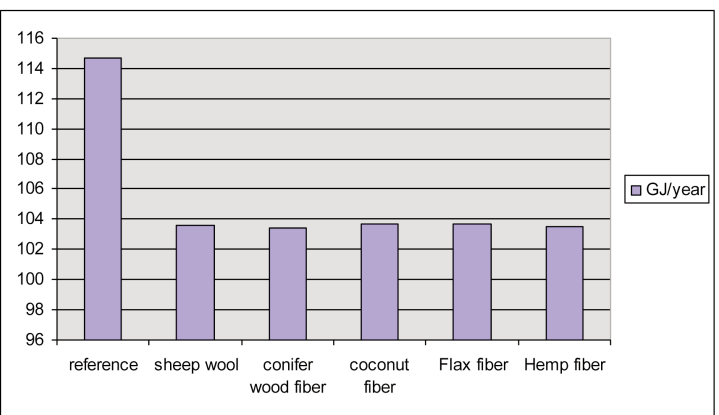

Figure 5. Site Energy results (Energy Plus simulation) for natural materials.

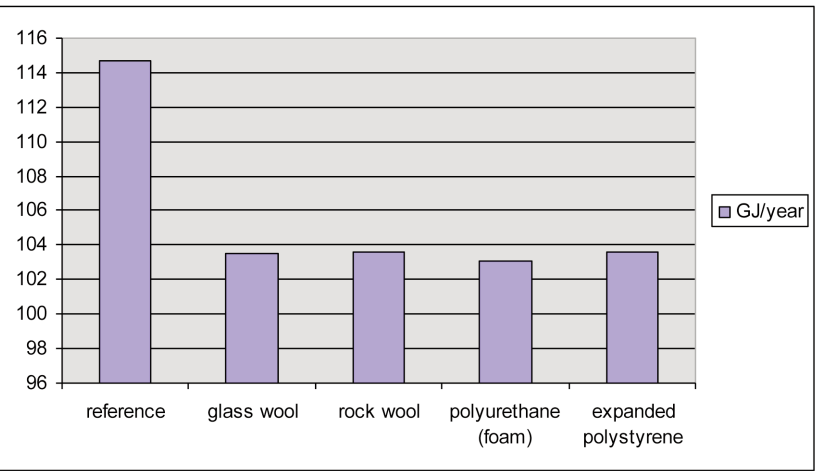

Figure 6. Site Energy results (Energy Plus simulation) for synthetic materials.

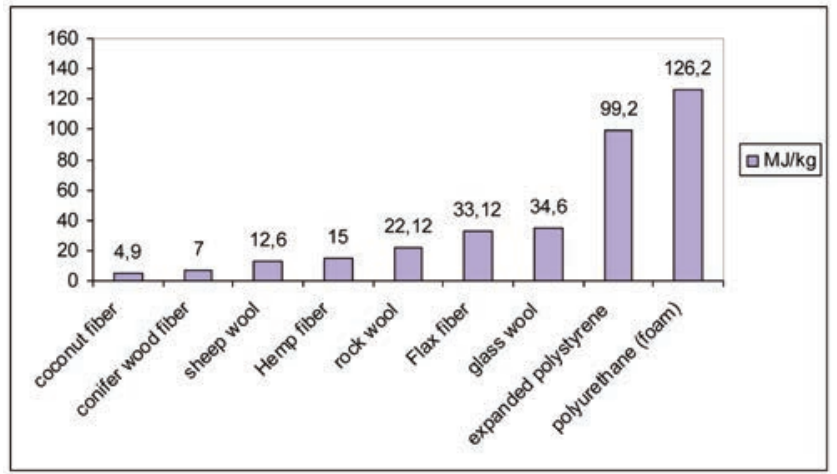

Figure 7. Primary Energy Input. 
where $y_{i}$ are the $x_{i}$ normalized value, Xmax and Xmin are respectively the maximum and the minimum value of $x_{i}$

From Table 4 it can be seen that, from the multicriteria analysis based on the considered parameters, the rock wool appears to be the best insulating material for the vertical walls of a buildings with the same localization characteristics. This material would be suitable for this type of applications as it's a widely used material with high availability and for its ease of installation.

Table 2. Material used to change vertical opaque surfaces in the case study.

\begin{tabular}{|c|c|c|c|c|c|}
\hline Material & $\begin{array}{l}\text { Thickness } \\
\text { (cm) }\end{array}$ & Origin & $\begin{array}{l}\text { Thermal conductivity } \\
\lambda(\mathrm{W} / \mathrm{m} \mathrm{K})\end{array}$ & $\begin{array}{l}\text { Density } \\
(\mathrm{kg} / \mathrm{m} 3)\end{array}$ & $\begin{array}{l}\text { Specific heat } \\
\text { (J/kg K) }\end{array}$ \\
\hline $\begin{array}{l}\text { Insulation } \\
\text { sheep wool } \\
\text { conifer wood fiber } \\
\text { coconut fiber } \\
\text { glass wool } \\
\text { rock wool } \\
\text { polyurethane (foam) } \\
\text { expanded polystyrene } \\
\text { Flax fiber } \\
\text { Hemp fiber }\end{array}$ & $\begin{array}{l}5 \\
5 \\
5 \\
5 \\
5 \\
5 \\
5 \\
5 \\
5\end{array}$ & $\begin{array}{c}\text { natural } \\
\text { natural } \\
\text { natural } \\
\text { synthetic } \\
\text { synthetic } \\
\text { synthetic } \\
\text { synthetic } \\
\text { natural } \\
\text { natural }\end{array}$ & $\begin{array}{c}0,037 \\
0,04 \\
0,043 \\
0,032 \\
0,04 \\
0,024 \\
0,036 \\
0,04 \\
0,039\end{array}$ & $\begin{array}{c}17,9 \\
150 \\
70 \\
13,5 \\
80 \\
34 \\
24 \\
30 \\
40\end{array}$ & $\begin{array}{c}1720 \\
2100 \\
1300 \\
850 \\
840 \\
1250 \\
800 \\
1660 \\
2100\end{array}$ \\
\hline $\begin{array}{l}\text { Plaster } \\
\text { plaster }\end{array}$ & 1 & & 1 & 1800 & 910 \\
\hline
\end{tabular}

Table 3. Considered criteria in the SAW analysis. Source of data: Site Energy is an output of Energy plus run simulation, PEI by Colombo (2006) and cost by Umbria Regional pricing 2012.

\begin{tabular}{lccc}
$\begin{array}{l}\text { Insulation alternatives } \\
\text { i:1-9 }\end{array}$ & $\begin{array}{c}\text { Site Energy }\left(\mathbf{x}_{1}\right) \\
\text { GJ }\end{array}$ & $\begin{array}{c}\text { PEI }\left(\mathbf{x}_{2}\right) \\
\text { MIJ/Kg }\end{array}$ & $\begin{array}{c}\text { Cost }\left(\mathbf{x}_{\mathbf{3}}\right) \\
\text { euro/m² }\end{array}$ \\
without insulation (reference) & 114.72 & 0 & 0 \\
sheep wool & 103,60 & 12,6 & 25 \\
\hline conifer wood fiber & 103,44 & 7 & 23,25 \\
coconut fiber & 103,65 & 4,9 & 29,2 \\
\hline glass wool & 103,48 & 34,6 & 7,2 \\
rock wool & 103,62 & 22,12 & 8,1 \\
\hline polyurethane (foam) & 103,05 & 126,2 & 18,88 \\
expanded polystyrene & 103,62 & 99,2 & 10,26 \\
\hline Flax fiber & 103,68 & 33,12 & 19,55 \\
Hemp fiber & 103,55 & 15 & 21,25 \\
\hline
\end{tabular}

Table 4. Simple Additive Weighting Results: S.

\begin{tabular}{|c|c|c|c|c|}
\hline Material & $\begin{array}{c}\text { Site Energy* } \\
\text { GJ/year }\end{array}$ & $\begin{array}{l}\text { PEI* } \\
\text { MJ/Kg }\end{array}$ & $\begin{array}{c}\text { Cost* } \\
\text { euro/m² }\end{array}$ & S \\
\hline without insulation (reference) & 0.00 & 1.00 & 1.00 & 2.00 \\
\hline sheep wool & 0.95 & 0.90 & 0.14 & 2.00 \\
\hline conifer wood fiber & 0.97 & 0.94 & 0.20 & 2.11 \\
\hline coconut fiber & 0.95 & 0.96 & 0.00 & 1.91 \\
\hline glass wool & 0.96 & 0.73 & 0.75 & 2.44 \\
\hline rock wool & 0.95 & 0.82 & 0.72 & 2.50 \\
\hline polyurethane (foam) & 1.00 & 0.00 & 0.35 & 1.35 \\
\hline expanded polystyrene & 0.95 & 0.21 & 0.65 & 1.81 \\
\hline Flax fiber & 0.95 & 0.74 & 0.33 & 2.01 \\
\hline Hemp fiber & 0.96 & 0.88 & 0.27 & 2.11 \\
\hline
\end{tabular}

$\left({ }^{*}\right.$ this columns show normalized parameters values) 
which are in service, is the most economical, in terms of both materials and labour, and the most sustainable in terms of materials PEI. But we must take into account that the costs, as they have been considered in the work, are related to the initial investment (and therefore refer only to the first year of operation), while the energy savings continue in subsequent years. This consideration is likely to lean toward different materials such as conifer wood fiber that appears to have a better performance of the rock wool, on the basis of the first two evaluation parameters Site Energy and PEI (Table 4). A necessary development of this research should include an analysis of performance variations including interventions on roofs and windows, because acting only on vertical opaque surfaces the objective of lowering to zero the energy requirement of the building, to achieve optimal environmental conditions, is not attainable. It is also clear that could emerge an issue about the feasibility of such interventions, considering the limited profit margins of enterprises with characteristics similar to the study case. These enterprises operate, and have always operated, in the absence of a dedicated HVAC system, and then to simulate its presence may appear to be forced, as we did to obtain the reference value used in the comparison. This choice may seem arbitrary, but it is not in view of the fact that, in the continuous search for improvement of our production facilities, towards greater environmental sustainability, achieving adequate standards, in terms of optimal environmental conditions for operators and animals, should be considered an essential starting point. On the other hand working with the aim of improving the environmental conditions for workers and animals could also led to the improvement of the productivity livestock performances and to the maintenance of high quality standards of products (Sevi A. et al., 2001; Sevi A. et al., 2003).

In an ideal situation it would be preferable to design the structures from scratch, incorporating in the process, in addition to the aspects listed above relative to the thermal inertia of the enclosure, also structural solutions such as the shape, orientation, and optimal distribution of the functional areas. However, this is often not feasible because of the high costs involved.

Trying to improve the existing structures, also in consideration of the contributions made in this regard by the EU in compliance with the principles of sustainability of the agricultural sector, is an objective actually pursuable.

\section{References}

Alireza A., Majid M., Rosnah M.Y., 2010. Simple Additive Weighting approach to Personnel Selection problem. International Journal of Innovation, Management and Technology. 1 (5), 511-515.

Agenzia Regionale per lo Sviluppo e l'Innovazione nel settore Agricoloforestale (ARSIA) Regione Toscana, 2006. Guida per la valorizzazione dei prodotti agroalimentari tipici (Guide for the valorisation of typical food products). ARSIA.
Capronese M., 2008. Sheep housing and welfare. Small ruminant research. 76, 21-25.

Chiappini U., Fichera R. C., Mennella V., 1994. Metaprogettazione per l'edilizia zootecnica (Meta-design for the livestock building). C.N.R.

Chiumenti R., 1987. Costruzioni rurali (Rural constructions). Edagricole.

Colombo G., 2006. Lo stato dell'arte nella progettazione passiva degli edifici (State of the art in the design of passive buildings). Alinea, Firenze.

European Commission, 2012. Agriculture, fishery and forestry statistics. Main results -2010-11, Eurostat, Retrieved from http://europa.eu;

Fabrizio E., Airoldi G., 2012. Simulazione termoenergetica dinamica di un edificio per l'allevamento suinicolo: strategie edilizie e impiantistiche per l'ottimizzazione del benessere termo igrometrico (Thermo-energetic dynamic simulation of a building for the swine farming: building and plant strategies for optimizing the welfare thermo hygrometric). AIIA 2012, Conference proceedings. Firenze, 20-22 September 2012.

Ihm P., Krarti M., 2012. Design optimization of energy efficient residential buildings in Tunisia. Building and Environment. 58, 81-90.

Jäkel K., 2003. Analyse der Elektroenergieanwendung und Einsparpotentiale am Beispiel sächsischer Milchviehanlagen (Analysis of the electrical energy input and saving potentials at the example of Saxon dairy farms). Forschungsbericht Agrartechnik, 414, Martin-Luther-Universität, Halle/Saale.

Kraatz S., Berg W., 2007. Energy demand for milking dairy cows. Asabe Annual Intl. Meeting, paper n. 074175, Minneapolis.

Rossi M., 2007. Soluzioni tecniche per involucri ad alta efficienza energetica. L'isolamento termico (Technical solutions for high energy efficiency enclosures. The thermal insulation). Costruire. 288, $72-$ 76.

Sevi A., Annicchiarico G., Albenzio M., Taibi L, Muscio A., Dell'Aquila S., 2001. Effects of solar radiation and feeding time on behaviour, immune response and production of lactating ewes under high ambient temperature. Journal of Dairy Science. 84, 629-640.

Sevi A., Albenzio M., Muscio A., Casamassima D., Centoducati P., 2003. Effects of litter management on airborne particulates in sheep houses and on the yield and quality of ewe milk. Livestock Production Science. 81, 1-9.

Thompson R., 2009. Sustainability of hill sheep flocks in England, Small Ruminant Research. 86, 71-73.

U.N.A.P.OC. (Unione Nazionale Associazioni Produttori Ovi-Caprini), 1992. Ovinicoltura (Sheep husbandry). UNAPOC.

Wang K.S.Y., Yik F.H.W., 2004. Representative building design and internal load patterns for modelling energy use in residential buildings in Hong Kong. Applied Energy. 77, 69-85.

Znouda E., Ghrab-Morcos N., Hadj-Alouane A., 2007. Optimization of Mediterranean building design using genetic algorithms. Energy and Buildings. 39, 148-153. 